\title{
ASPECTOS E COMPORTAMENTOS ERGONÔMICOS NO TELETRABALHO
}

\section{ERGONOMIC ASPECTS AND BEHAVIORS IN TELEWORKING}

\author{
Matheus de Oliveira * E-mail: matheusdeoliveira1991@gmail.com \\ Sandro Keine* E-mail: sandro.keine@udesc.br \\ *Universidade do Estado de Santa Catarina (UDESC), Florianópolis, SC
}

\begin{abstract}
Resumo: O fenômeno do teletrabalho, que já era aplicado em alguns setores e empresas, veio como solução fundamental para a manutenção econômica durante a pandemia de COVID-19 vivenciada em 2020. Ocorre, porém, que com a necessidade e urgência que a situação calamitosa requereu, alguns cuidados podem não ter sido tomados na transição para essa forma de trabalho, especialmente os ergonômicos. O presente artigo busca correlacionar as orientações e cuidados ergonômicos das empresas e teletrabalhadores, utilizando-se para tanto, como método, a pesquisa de forma quantitativa do tipo descritiva. Para isso, optou-se pela aplicação de um questionário online, de forma a abranger um maior número de pessoas para formação do objeto deste estudo. Suas respostas permitem a identificação do teletrabalhador, bem como as orientações recebidas acerca do tema pelo seu empregador, além dos cuidados tomados, seja por livre iniciativa ou orientação da empresa. É a partir da análise quantitativa desses casos concretos, que o trabalho colabora para a compreensão dos aspectos ergonômicos, demonstrando que as ações de orientações ergônomicas dos empregadores acarretam um maior cuidado ergonômico do teletrabalhador, podendo se tornar importante fonte de informação útil às empresas para futuras implementações de teletrabalho.
\end{abstract}

Palavras-chave: Teletrabalho. Ergonomia. Home office. Trabalho Flexivel.

Abstract: The telecommuting phenomenon, that was already applied in some sectors and companies, was a fundamental solution for economic maintenance during the COVID-19 pandemic crisis experienced in 2020. However, with the need and urgency that the calamitous situation required, some cares may not have been taken for the transition to that way of work, specially the ergonomic. The present article seeks correlate the orientations and de ergonomic cares of the companies and telecommuter, using for such, as method, the quantitative research in the descriptive way. To do this, it has been opted for the application of an online questionnaire, in order to cover a larger number of people to form the object of this study. Its responses select the identification of the telecommuter, as well as the guidance received on the topic by their employer, in addition to the care taken, whether by free initiative or company guidance. It is from the quantitative analysis of these real cases, that the work collaborates to understand the ergonomic aspects, showing that the decision of the employers in giving ergonomic orientations leads to a bigger ergonomic caution by the telecommuter and also can become an important source of useful information for companies for future telecommuting implementations.

Keywords: Telecommuting. Ergonomic. Flexible Working.

\section{INTRODUÇÃO}

A globalização traz consigo um aumento significativo da concorrência e da mobilidade profissional (GRECO; MARTINS, 2001). Em decorrência desse fenômeno observa-se que cada vez menos o Estado interfere nas questões 
corporativas, e cada vez mais tem-se um binômio entre alta tecnologia e baixos salários (MANNRICH apud WINTER, 2005). Concomitante à alta tecnologia há o crescimento do trabalho intelectual, ou seja, aquele que depende mais do conhecimento especializado do que de máquinas ou ferramentas específicas. Esse tipo de trabalho, muitas vezes, não demanda que o funcionário ocupe um espaço físico no escritório, como na "visão clássica" de trabalho, ele pode ser realizado à distância, em casa, na estrada ou em qualquer outro local (KUGELMASS, 1996). Como decorrência disso, há um aumento da qualidade de vida daquele que o faz, seja por reduzir o tempo e custos do deslocamento até o emprego, pela autonomia dos horários e métodos, por poder trabalhar cuidando dos filhos, entre outros benefícios, fatores esses que o tornam desejado por muitos profissionais e ainda incentivado pelos empregadores, já que reduz os custos com imóveis, valetransporte, café, despesas de água, luz, entre outros (WINTER, 2005). Por essas e outras vantagens o teletrabalho está avançando rapidamente nos últimos tempos (BLUEPRINT apud SOUZA, 2005, p.5).

No final do ano de 2019 o mundo todo observou o surgimento de um novo e mortal vírus, que desencadeia uma doença nomeada COVID-19, cujo alto potencial de contágio e elevada taxa de letalidade, fez governos em diversos continentes passarem a adotar a quarentena obrigatória, mantendo-se apenas serviços considerados essenciais em funcionamento, a exemplo de mercados, farmácias e serviços hospitalares. A situação suprarreferida fez com que $43 \%$ das empresas adotassem o esquema de teletrabalho para seus empregados (VALOR, 2020).

Sabe-se que o trabalho remoto é um desafio aos sistemas produtivos tradicionais, especialmente por exigir flexibilização na forma da gestão da produção (WINTER, 2005). Podemos dizer que nem todos estão preparados para a implementação desse serviço à distância, seja por deixar de lado importantes questões de ergonomia (HARRINGTON; WALKER apud SOUZA, 2005), ou ainda por exigir um maior grau de autonomia do trabalhador (JARDIM, 2003).

É nesse contexto, extremamente atual, que se justifica a elaboração do presente artigo, tornando possível que, através das conclusões do estudo realizado, possa-se entender um pouco mais acerca dos problemas vivenciados pelos trabalhadores na transição do trabalho físico para o teletrabalho, especialmente no aspecto ergonômico, que influencia diretamente na saúde do empregado e na 
responsabilidade do empregador.

\section{REVISÃO DE LITERATURA}

Para a revisão de literatura foram abordados temas de relevância para o presente trabalho, analisando-se artigos pesquisados nos periódicos a partir da utilização de palavras-chaves acerca do assunto, além de livros, leis e demais publicações acerca dos temas compreendidos, empregando-se fontes clássicas e atuais. Foi constatada a existência de muitos trabalhos a respeito da ergonomia nos mais diversos postos de trabalhos, mas raros abordam o tema no teletrabalho especificamente, destes, pode ser citada a dissertação de engenharia de Oliveira (1996) na qual se aborda o tema proposto.

\subsection{Teletrabalho}

A partir da década de 50, o surgimento do computador trouxe inúmeras transformações aos centros de produções. Já nos anos 80, com o início do "boom" tecnológico, adveio a necessidade de um reajustamento social e político, ocorrendo o aumento do desemprego industrial, e fazendo surgir novos setores da produção, como os de serviços e financeiros (ANTUNES, 1995).

Teletrabalho é o fenômeno que ocorre quando o trabalho convencional passa a ser realizado longe dos escritórios, colegas de serviço, e centros de produções, com auxílio e utilização da tecnologia da informação para comunicação independente (MOTTA apud MIRA, 2004). Nesse tipo de trabalho, empregados e gestores acessam as informações profissionais de locais remotos (PÉREZ et al., 2004).

O surgimento do teletrabalho deu-se primeiramente com pequenas tarefas, e foi somente com o decorrer do tempo que passaram a ser realizadas atividades de maior complexidade (SHIN; SHENG; HIGA, 2000). Não se sabe exatamente onde e quando começou essa espécie de trabalho à distância, mas um dos seus primeiros registros é de 1857, quando J. Edgard Thompson, proprietário da Estrada de Ferro Penn, administrou algumas divisões de forma remota, com o auxílio de um sistema particular de telégrafo da sua companhia, delegando a mão de obra e o controle de equipamentos a funcionários (KUGELMASS, 1996).

Revista Produção Online. Florianópolis, SC, v. 20, n. 4, p. 1405-1434, 2020. 
O célebre escritor brasileiro Monteiro Lobato, na obra o Presidente Negro, datada de 1926, já previa que em dado momento os trabalhadores não mais utilizariam o sistema de transporte para ir até o local de trabalho e teriam a possibilidade de realizar o serviço em casa (CRISTALDO, 1998).

A legislação brasileira passou a prever o teletrabalho e suas condições na Consolidação das Leis do Trabalho (CLT), a partir da reforma trazida pela Lei 13.467 de 2017. Dessa forma, o instituto passou a ser conceituado no art. 75-B, que dispõe que o teletrabalho é qualificado como a prestação de serviços realizada preponderantemente fora das acomodações do empregador, utilizando-se de tecnologias de informação e comunicação que, dada sua natureza, não seja considerada simples trabalho externo. Algumas alterações são trazidas com a mudança para o teletrabalho, por exemplo, a retirada de benefícios como refeições e transporte e o acréscimo de auxílios para internet e equipamentos.

Por permitir uma melhor gestão de tempo e reduzir o estresse com os deslocamentos entre o lar e o trabalho, verifica-se uma maior produtividade no teletrabalho do que no serviço tradicional (WINTER, 2005). Segundo Kugelmass apud Winter (2005) há diversos estudos que demonstram um aumento de produtividade pelos teletrabalhadores, sendo que um dos principais motivos que contribuiria para esse resultado seria a maior capacidade de lidar com os conflitos familiares, haja vista possuir maior autonomia nos horários, e ainda estar mais próximos aos entes queridos.

Há também o fato de que o atendimento ao cliente pode ser ampliado para horários menos convencionais, uma vez que não há horário fixo para a realização do trabalho. Essa modalidade também reduz a rotatividade, pelo fato de acarretar a redução dos custos da empresa com treinamento e, consequentemente aumentando a produtividade, pois os profissionais já possuem maior familiaridade e conhecimento dos produtos e procedimentos da empresa (MANOOCHEHRI; PINKERTON, 2003).

Deve-se ressaltar, no entanto, que a alta produtividade no teletrabalho não deve implicar no aumento da jornada laboral. É fundamental que os trabalhadores respeitem os horários, para que não se aumente a duração de suas atividades de forma desenfreada, o que pode trazer riscos associados à intensidade. 


\section{2 Vantagens e Desvantagens do Teletrabalho}

Podemos classificar as vantagens e desvantagens do teletrabalho sob três óticas: a do trabalhador, a do empregador e a da sociedade. Sob o primeiro prisma, do trabalhador, temos inúmeras vantagens, como: flexibilidade das horas de trabalho; possibilidade de participação mais ativa de idosos e deficientes no mercado de trabalho; liberdade em relação ao uso de uniformes; diminuição ou eliminação do tempo de deslocamento casa-trabalho-casa; adaptação do ritmo profissional ao ritmo familiar/pessoal; e diminuição dos níveis de estresse e ansiedade (KANTER, 2010).

Em contrapartida, deve-se salientar que nem todos são pontos positivos, portanto, quanto aos aspectos negativos, temos: isolamento social; redução do espaço físico do lar; aumento dos custos pessoais; perdas dos benefícios profissionais; maior dificuldade de crescimento profissional; dificuldade de separar a vida pessoal e profissional; e, consequentemente, jornadas de trabalho mais extensas. Além disso, há ainda a falta de clareza da legislação nacional sobre a regulementação do teletrabalho, o que pode ensejar insegurança jurídica no campo do direito do trabalho, não só para o empregado, como para o empregador. Tendose em mente os aspectos negativos suprarreferidos, deve-se ressaltar que empresas como a Best Buy e o Yahoo já utilizavam o home office, mas interromperam a prática devido a ausência de comprometimento dos seus colaboradores (ÉPOCA, 2013).

Ainda que o exposto acima seja levado em consideração, a World Economic Forum (2020) realizou uma pesquisa com teletrabalhadores durante a Coronacrise e, restou evidenciado que $98 \%$ dos entrevistados gostariam de continuar realizando seu trabalho de forma remota, ao menos em parte do tempo, pelo resto de suas respectivas carreiras.

No que tange às empresas, as vantagens consideradas podem ser: redução de utilização de espaços; redução de custos (com custos fixos transformando-se em variáveis); melhora da imagem da empresa frente aos clientes e à sociedade; e maior produtividade. Porém, as principais desvantagens são: menor identificação do colaborador com a instituição; dificuldade de avaliação de produtividade; falta de visibilidade; dificuldade de crescimento na carreira dos teletrabalhadores em função da dificuldade dos gestores em analisar a produtividade (MARTINEZ-SANCHES et 
al., 2007); alto investimento em tecnologia da informação; e aumento da insegurança laboral.

A sociedade também sente os impactos do teletrabalho, com a redução no trânsito em decorrência da diminuição do fluxo de veículos, minimizando, inclusive, a poluição e permitindo que os moradores interajam mais tempo com sua comunidade local. Em contrapartida, os grandes centros comerciais sofrem com a falta do volume de pessoas, e, por sua vez, as redes de internet e eletricidade podem não suportar o tráfego intenso utilizado para essas operações.

\subsection{Ergonomia}

A ergonomia se apresenta como uma interdisciplina, em outras palavras, seus conhecimentos têm origem em diversas áreas do conhecimento, cujo objetivo é estudar e otimizar a relação entre homem e trabalho como um todo, analisando seus equipamentos, ambiente e relações, para assim, buscar adequar esse conjunto a suas características, de forma a eliminar condições de insegurança, ineficiência, desconforto ou insalubridade. Para que se tenha noção de sua abrangência, a ergonomia reúne conceitos de filosofia, medicina, físico-química, fisiologia, engenharia de produção, entre outros (VIDAL, 2000). É correto dizer, portanto, que os conceitos utilizados por essa disciplina não são criações exclusivas dela, porém a metodologia de que se utiliza para organizar e aplicar esses conhecimentos são, de fato, da ergonomia.

Assim como o é com o teletrabalho, não é possível precisar exatamente onde, quando e como iniciaram-se os estudos ergonômicos. Pesquisas apontam que na pré-história as ferramentas já sofriam alterações de tamanhos para facilitar os respectivos manuseios; ainda no Egito antigo, já haviam recomendações ergonômicas para a construção civil, por exemplo. A primeira vez que Ergonomia foi definida cientificamente se data de 1857, como sendo a junção de dois termos gregos "Ergos", cujo sugnificado é "trabalho", e "Nomos", que pode ser traduzido por "leis". Buscava compreender o esforço, pensamento e os relacionamentos profissionais (KARWOWSKY apud VIDAL, 2000).

Oficialmente, apenas em 1949, com o surgimento da Ergonomics Research Society é que foi criada a Ergonomia propriamente dita (ILDA, 2005), que 
inicialmente surgiu mais como uma ciência dos fisiologistas e profissionais da saúde, para, por volta do ínicio do século $\mathrm{XX}$, passar a ser mais estudada pelos engenheiros industriais.

A essa altura, importa salientar que a ergonomia possui as mais diversas aplicações práticas e cotidianas. Por óbvio, nesse estudo, estamos tratando da ergonomia aplicada ao setor produtivo, relacionada à adaptação ao teletrabalho, porém ela pode ser aplicada nos mais diversos setores industriais (no aperfeiçoamento de máquinas ou equipamentos e também treinamentos de operários) ou de serviços, assim como na qualidade de vida das pessoas, nas atividades domésticas e até de lazer, podendo ser observada na qualidade de produtos, através de inúmeros testes de segurança e desempenho.

Como disciplina, seu objetivo é principalmente a saúde e segurança dos trabalhadores, identificando riscos e buscando minimizá-los, sempre tentando maximizar sua satisfação e motivação profissional, visando a uma maior produtividade. Em suma, podemos dizer que a ergonomia busca a melhor adaptação do ambiente ao homem, com o objetivo final de otimizar as condições de serviço, de forma a assegurar que sua saúde não será comprometida (SANTOS; SILVA; CARVALHO, 2017). Já como aplicação prática, assevera-se que o foco da ergonomia é, sem dúvidas, modificar o sistema de trabalho de forma realista, mas também efetiva, em outras palavras, seu foco é viabilizar mudanças a partir da compreensão elaborada em cima da realidade de certa atividade analisada.

Para Abergo (2020) a ergonomia pode ter 3 classificações: ergonomia física, cognitiva e organizacional, nas quais se referem, respectivamente, aos estudos fisiológicos, aos processos mentais e à cultura organizacional. Já para Ilda (2005), a ergonomia pode se classificar nas 4 seguintes áreas: ergonomia da concepção, que ocorre no momento do projeto; ergonomia de correção, cujo objetivo é solucionar um problema já verificado; ergonomia de conscientização, através da qual se busca capacitar os profissionais, para que os próprios possam corrigir erros diários e emergenciais; e a ergonomia de participação, aquela que engloba o usuário na resolução do problema ergonômico.

No Brasil, há uma Norma Regulamentadora específica para a ergonomia, instituída pelo Ministério do Trabalho e Previdência Social, a NR17, baixada pela Portaria n. 3.751 em 23.11.1990. Na suprarreferida norma, determinam-se padrões 
sobre levantamento, transporte e descarga individual de materiais; mobiliário dos postos de trabalho; equipamentos dos postos de trabalho; condições ambientais de trabalho; e organização do trabalho. Esses padrões ensejam a possibilidade de adaptação das condições de trabalho às características psicofisiológicas de cada trabalhador, sendo que caberá ao empregador realizar um estudo dos postos de trabalhos para que, de acordo com a norma se possa determinar as condições de trabalho (SOARES; MEDEIROS; NETO, 2017).

\subsection{Ergonomia no teletrabalho}

O espectro de atuação da ergonomia deixou de ser apenas industrial, e expandiu-se para todas as áreas de produção, como agricultura e serviços. Podemos compreender a ergonomia como uma atitude profissional, e como tal, muitas vezes é desrespeitada ou mal compreendida pelos trabalhadores que não the dão a importância devida. Uma das maiores dificuldades da ergonomia no teletrabalho se dá pela falta de fiscalização e análises reais, dificultando seus estudos.

A maior dificuldade do estudo ergonômico no teletrabalho se dá em razão do fato de que cada teletrabalhador desenvolve estações de trabalho diferentes, além de hórarios que podem impactar em fatores como ruídos, vibrações e iluminação. Por isso, a ergonomia necessita de uma maior adaptabilidade ao teletrabalho, uma vez que é realizada em um ambiente informal e familiar (OLIVEIRA, 1996). Outro aspecto a se levar em conta nessa melhor adequação é o fato de que o teletrabalho se encontra em grande parte inserido no setor de serviços, o que atrai o desempenho por idosos, mulheres com filhos, e até pessoas com necessidades especiais.

Quanto à inserção do teletrabalho no domicílio em meio à situação pandêmica atual, deve-se levar em consideração que houve uma transição forçada para essa forma de trabalho em razão da quarentena, em razão disso, muitos trabalhadores não tiveram tempo de se organizar para sua realização, visto que a realidade é que nem todos possuem uma cadeira adequada à atividade profissional, o mesmo podese dizer em relação à mesa ou à iluminação do ambiente que dispõe para trabalhar. 
Além disso, muitos não possuem o mínimo conhecimento da necessidade dos instrumentos e ambiente aptos a colaborar para uma jornada segura e salubre, motivo pelo qual o presente estudo torna-se relevante, no intuito de avaliar, também, o nível de responsabilidade do empregador para com seus trabalhadores. Em uma realidade ideal, o empregador deverá instruir seus empregados, de maneira expressa e sobremaneira ostensiva, quanto às precauções que devem ser tomadas no chamado "home-office", a fim de evitar doenças e acidentes de trabalho, em especial os evitáveis com boas práticas de ergonomia.

$\mathrm{Na}$ ergonomia não há uma solução universal, tendo-se que efetuar o estudo casuístico (SPERANDIO, 1989), e isso se torna ainda mais complicado em ambientes de teletrabalho, onde uma solução utilizada em uma estação, pode ser problemática em outra, devendo-se sempre levar em consideração as diferenças individuais dos trabalhadores e mobiliários, considerando as especificidades de cada ambiente. Como dito anteriormente, o foco da ergonomia é viabilizar mudanças a partir da compreensão elaborada sobre a realidade de certa atividade, sendo assim, também no teletrabalho, a aplicação correta da ergonomia apoia-se em um estudo aprofundado do caso de teletrabalho que visa-se modificar, incluindo as mais diversas variáveis que podem interferir em cada ocasião.

Importa ressaltar que a utilização de equipamentos ditos ergonômicos, por si só, não é suficiente para a obtenção de bons resultados. Isso quer dizer que a ergonomia não é resultado exclusivo das características dos equipamentos utilizados, mas é definida especialmente pela interação desenvolvida entre o utilizador e o objeto. Por isso, o mais importante na ergonomia no teletrabalho é a capacitação dos teletrabalhadores com treinamentos, bem como reciclagens, a respeito do tema, para que se conscientizem de práticas corretas e de cunho universal.

Algumas práticas podem ser sugeridas, mas, como dito anteriormente, não há um manual universal. Inicialmente, é fundamental determinar um local de trabalho adequado, onde haja privacidade, baixa movimentação, a fim de evitar interrupções indesejadas, e preferencialmente que tenha algum isolamento acústico. Interessante que seja um ambiente com cores que estimulem a criatividade, e obrigatoriamente com boa ventilação, temperatura e iluminação. Em alguns casos, como os dos que utilizam equipamentos elétricos/eletrônicos de alta potência, é importante observar a 
tensão suportada pela rede do local. O mobiliário também deve ser adequado, utilizando-se uma mesa de escritório ou bancada que caiba suas pernas embaixo e todo o equipamento necessário em cima, além de uma cadeira confortável com rodízio, regulagem de altura e apoio de braços.

Caso haja a utilização de notebooks, faz-se importante o uso de monitor externo ou suporte para o notebook para não sobrecarregar o pescoço. É de grande proveito também a utilização de periféricos como mouse e teclado externo, o que também colabora de forma efetiva para a redução de fadiga e riscos de lesões. Quando houver a utilização de telefone, é relevante utilizar fones de ouvidos ou aparelhos com função viva-voz, evitando novamente a sobrecarga no pescoço. O trabalhador deve ainda se programar para que consiga realizar os intervalos, que além de serem obrigatórios por lei, são de fundamental importância para a saúde e a manutenção da produtividade. Deve-se ter cuidado no arranjo dos materiais para evitar acidentes, como por exemplo, evitando objetos pontiagudos virados para cima, além de sempre dispor de forma prática os equipamentos mais utilizados. O cuidado com a postura é fundamental, além do que, é recomendada a realização de alongamentos antes e após o trabalho (SESI-PR, 2020).

\section{METODOLOGIA}

Para a fundamentação do artigo foi realizada tanto pesquisa bibliográfica, através da utilização de livros, artigos, entre outras publicações (VERGARA, 2005), de forma a permitir a criação de um referencial teórico apto à demonstração da importância do tema; quanto coleta de dados através de questionário online, com aptidão de promover a análise que é objetivo desse estudo.

O que irá sugerir a metodologia a ser utilizada é, conforme destaca Silverman (2009), o problema objeto do presente trabalho, qual seja, a relação entre as recomenções ergonômicas dos empregadores e as práticas adotadas ou não pelos empregados. Quanto ao método em si, foi utilizada a pesquisa sob a forma quantitativa (RICHARDSON, 1999), do tipo descritiva (CERVO; BERVIAN; SILVA, 2007).

A população objeto do levantamento é formada por teletrabalhadores. A amostra foi do tipo não probabilística e o critério de seleção foi a acessibilidade, ou 
seja, selecionando-se os elementos pela facilidade de acesso a eles (VERGARA, 2005).

Seguindo as orientações de Cervo, Bervian e Da Silva (2007), deve ser dada fundamental importância para a fase intermediária da pesquisa, sendo ela, a coleta de dados, pois esta deve ser bem planejada a fim de obter-se dados mais úteis e que representam a realidade da situação em questão. Um dos passos descritos pelos autores na parte da coleta se dá no instrumento de coleta, que nesse caso foi um questionário dividido em identificação do perfil do teletrabalhador, as recomendações dos empregadores e as medidas adotadas pelos empregados.

O formulário será aplicado pela internet através da plataforma Google Forms. Para melhor visualização dos dados será utilizado auxilio do software MS Office Excel, para agrupamento dos dados e geração de gráficos que permitam a análise do resultado, buscando correlacionar o comportamento de pessoas e empresas referente ao teletrabalho.

A fim de elucidar o método a ser utilizado, foi elaborado o Quadro 1:

Quadro 1 - Metodologia

(Continua)

\begin{tabular}{|l|l|}
\hline \multicolumn{2}{|c|}{ Etapa 1 } \\
\hline Objetivo & $\begin{array}{l}\text { Contextualizar e entender o problema do artigo: Se houveram } \\
\text { preocupações com as questões ergonômicas por parte das } \\
\text { empresas e dos teletrabalhadores. }\end{array}$ \\
\hline Ação & $\begin{array}{l}\text { Pesquisar conteúdos acadêmicos acerca do tema proposto, } \\
\text { contextualizando-o. }\end{array}$ \\
\hline Objetivo & \multicolumn{1}{|c|}{ Etapa 2 } \\
\hline Ação & $\begin{array}{l}\text { Pesquisar e contextualizar referencial teórico acerca dos principais } \\
\text { tópicos do assunto: teletrabalho, vantagens e desvantagens do } \\
\text { teletrabalho, ergonomia, ergonomia no teletrabalho. }\end{array}$ \\
\hline & $\begin{array}{l}\text { Pesquisar conteúdos acadêmicos acerca dos assuntos, redigindo } \\
\text { texto que os explique. }\end{array}$ \\
\hline Objetivo & \multicolumn{1}{|c|}{ Etapa 3 } \\
\hline Ação & $\begin{array}{l}\text { Definir questões fundamentais sobre o tema para elaboração de } \\
\text { questionários. }\end{array}$ \\
\hline & $\begin{array}{l}\text { Elaborar questionário de pesquisa quantitativa, em que o } \\
\text { pesquisado não tenha interferência do pesquisador. }\end{array}$ \\
\hline
\end{tabular}

Revista Produção Online. Florianópolis, SC, v. 20, n. 4, p. 1405-1434, 2020. 


\begin{tabular}{|l|l|}
\hline \multicolumn{2}{|c|}{ Etapa 4 } \\
\hline Objetivo & Coletar os dados para a pesquisa. \\
\hline Ação & $\begin{array}{l}\text { Efetuar a pesquisa de campo, enviando os questionários via } \\
\text { internet para os teletrabalhadores acessíveis. }\end{array}$ \\
\hline \multicolumn{1}{|c|}{ Etapa 5 } \\
\hline Objetivo & Analisar os dados obtidos. \\
\hline Ação & $\begin{array}{l}\text { Analisar os dados com auxílio do software Excel, eliminando os } \\
\text { dados irrealísticos e tentando correlacioná-los em da } \\
\text { elaboração do resultado. }\end{array}$ \\
\hline & \multicolumn{1}{|c|}{ Etapa 6 } \\
\hline Objetivo & Obter resultado da pesquisa \\
\hline Ação & $\begin{array}{l}\text { Com os dados correlacionados iremos analisar o índice de } \\
\text { recomendações das empresas, e se os teletrabalhadores os estão } \\
\text { seguindo ou tomando cuidados por sua conta, ou outras razões por } \\
\text { exemplo. }\end{array}$ \\
\hline
\end{tabular}

Fonte: Autoria Própria (2020)

\section{RESULTADOS E DISCUSSÃO}

Esta seção trata pormenorizadamente dos resultados que foram obtidos após exame empírico. De início, será apresentada uma verificação detalhada das variáveis envolvidas na pesquisa, de forma a caracterizar os artigos em análise, para somente após, serem expostas as respectivas relações que puderam ser realizadas entre as variavéis.

\subsection{Análise das Variáveis}

A pesquisa foi realizada da forma já descrita na metodologia: através da aplicação de formulário pela internet, em meados do mês de maio do ano de 2020. Ao todo, 194 teletrabalhadores responderam a um questionário minuciosamente elaborado, o qual foi dividido em 4 grandes grupos, a saber: perfil dos entrevistados; orientações da empresa; cuidados tomados pelos entrevistados; e dores sentidas pelos entrevistados.

O perfil dos questionados foi formado por teletrabalhadores de diferentes áreas, idades e gêneros, porém a maioria estava dentro da faixa etária de 22 a 34 anos, cujo grau de instrução é igual ou acima de superior completo e que trabalham 
em nível operacional, conforme pode ser visualizado na Tabela 1 de frequência, bem como na Figura 1 de gráficos.

Tabela 1 - Tabela de frequência do perfil dos entrevistados

\begin{tabular}{l|r|l}
\multicolumn{3}{c}{ Gênero } \\
\hline Masculino & 109 & $56,2 \%$ \\
\hline Feminino & 85 & $43,8 \%$ \\
\hline
\end{tabular}

\begin{tabular}{l|r|r}
\multicolumn{3}{c|}{ Faixa etária? } \\
\hline Até 21 anos & 5 & $2,6 \%$ \\
\hline Entre 22-34 anos & 141 & $72,7 \%$ \\
\hline Entre 35-47 anos & 31 & $16,0 \%$ \\
\hline Entre 48-60 anos & 15 & $7,7 \%$ \\
\hline Maior que 60 anos & 2 & $1,0 \%$ \\
\hline
\end{tabular}

Grau de instrução

\begin{tabular}{l|r|r}
\hline Ensino Fundamental & 1 & $0,5 \%$ \\
\hline Ensino Médio/Técnico & 6 & $3,1 \%$ \\
\hline Ensino Superior Incompleto & 35 & $18,0 \%$ \\
\hline Ensino Superior Completo & 79 & $40,7 \%$ \\
\hline Pós-graduado & 73 & $37,6 \%$ \\
\hline
\end{tabular}

Tipo de hierarquia

\begin{tabular}{l|r|l}
\hline Gerência & 52 & $26,8 \%$ \\
\hline Operacional & 121 & $62,4 \%$ \\
\hline Direção & 21 & $10,8 \%$ \\
\hline
\end{tabular}

Tipo de contratação

\begin{tabular}{l|r|l}
\hline PJ & 43 & $22,2 \%$ \\
\hline CLT & 119 & $61,3 \%$ \\
\hline Funcionário Público & 32 & $16,5 \%$ \\
\hline
\end{tabular}

Fonte: Autoria Própria (2020) 
Figura 1 - Figura de Gráficos do Perfil.

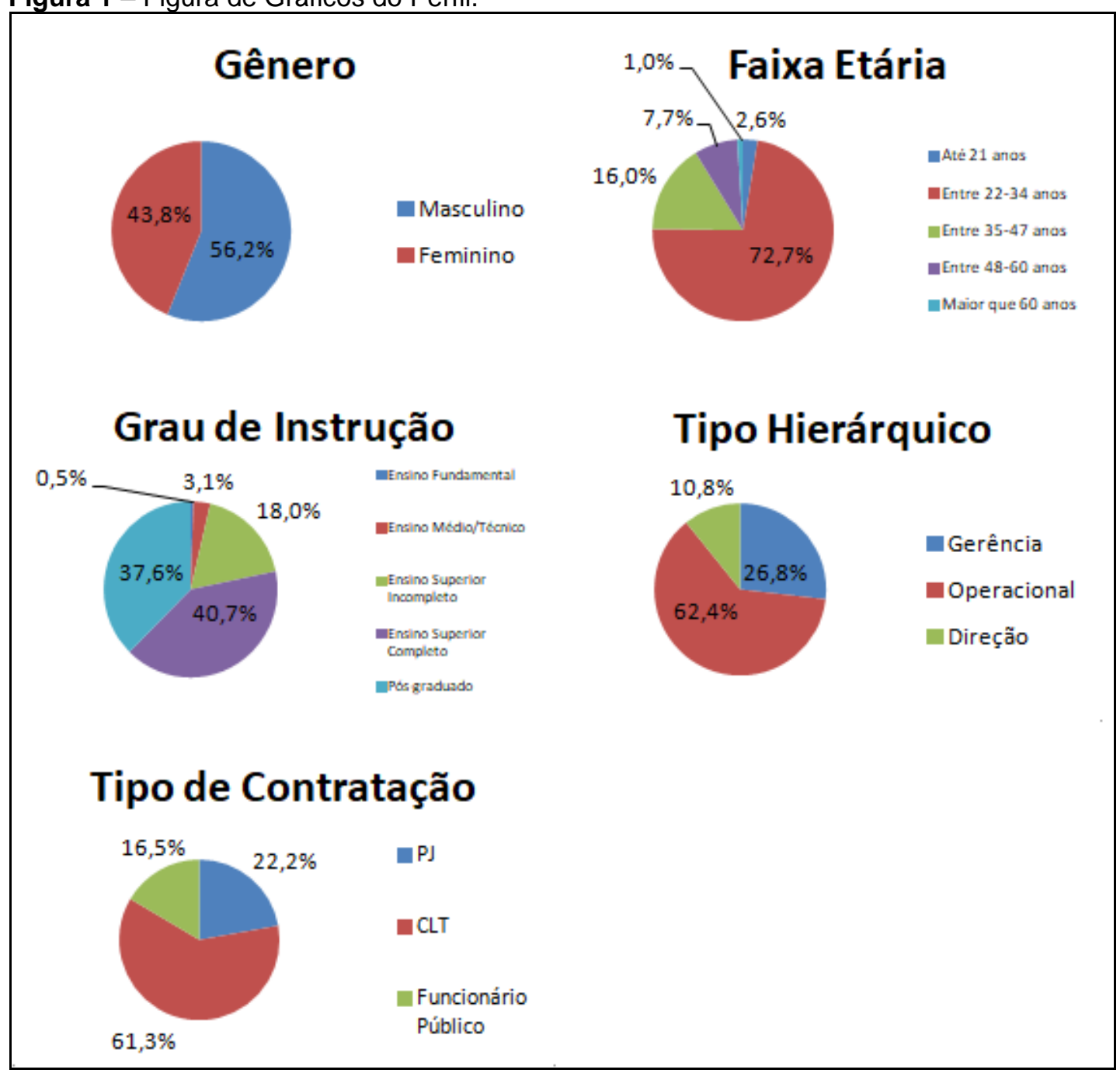

Fonte: Autoria Própria (2020)

$\mathrm{Na}$ segunda parte do questionário, que tratou sobre as orientações das empresas aos teletrabalhadores, fora perguntado se houve algum tipo de orientação acerca dos seguintes temas no ambiente de trabalho: ruídos sonoros, iluminação, vibrações, temperatura, postura, adequação da mesa, adequação do assento, espaço-físico utilizado, tempo máximo de jornada de trabalho, tempo de intervalo diário, folga semanal, realização de alongamentos, utilização de periféricos em notebook e o fornecimento de ferramentas para o serviço. Em caso de resposta afirmativa à existência de orientação, foi questionado ainda se a orientação fornecida se mostrou superficial ou se houve um maior detalhamento para que não houvessem dúvidas a respeito.

Segundo os dados obtidos com os entrevistados, as empresas pouco ou nada se preocuparam em orientar seus colaboradores sobre questões ergonômicas, seja 
por desconhecimento, ou pela falta de tempo e preparo, já que em questões de semanas houve uma brusca mudança do mundo em decorrência da atual pandemia. Tendo-se isso em conta, os temas mais orientados foram a manutenção de folgas semanais, os intervalos intrajornada e a adequação da postura corporal, enquanto que os menos orientados foram acerca das vibrações e temperatura. Do total de entrevistados, 22 (11\%) alegam não ter recebido nenhuma orientação acerca dos temas, apesar disso, mais da metade dentre eles, ou seja, 12 indivíduos receberam da empresa algum tipo de ferramenta para a realização do teletrabalho. $\mathrm{Na}$ contramão desse dado, apenas 11 (5,5\%) dos entrevistados receberam algum tipo de orientação que englobasse todos os temas questionados nesta etapa, sendo que 4 dentre eles afirmaram ter recebido orientações detalhadas em todos os temas. $A$ Tabela 2 e a Figura 2 demonstram os dados acerca das orientações das empresas.

Tabela 2 - Tabela de frequência das orientações das empresas

\begin{tabular}{|c|c|c|c|c|c|}
\hline \multicolumn{3}{|c|}{ Orientações sobre ruídos sonoros } & \multicolumn{3}{|c|}{ Orientações sobre espaço físico } \\
\hline Sim, detalhadamente & 23 & $11,86 \%$ & Sim, detalhadamente & 35 & $18,04 \%$ \\
\hline Sim, superficialmente & 40 & $20,62 \%$ & Sim, superficialmente & 42 & $21,65 \%$ \\
\hline Não & 131 & $67,53 \%$ & Não & 117 & $60,31 \%$ \\
\hline \multicolumn{3}{|c|}{ Orientações sobre iluminação } & \multicolumn{3}{|c|}{ Orientações sobre tempo de jornada } \\
\hline Sim, detalhadamente & 27 & $13,92 \%$ & Sim, detalhadamente & 59 & $30,41 \%$ \\
\hline Sim, superficialmente & 38 & $19,59 \%$ & Sim, superficialmente & 46 & $23,71 \%$ \\
\hline Não & 129 & $66,49 \%$ & Não & 147 & $75,77 \%$ \\
\hline \multicolumn{3}{|c|}{ Orientações sobre vibrações } & \multicolumn{3}{|c|}{ Orientações sobre intervalos intrajornada } \\
\hline Sim, detalhadamente & 15 & $7,73 \%$ & Sim, detalhadamente & 55 & $28,35 \%$ \\
\hline Sim, superficialmente & 23 & $11,86 \%$ & Sim, superficialmente & 49 & $25,26 \%$ \\
\hline Não & 156 & $80,41 \%$ & Não & 90 & $46,39 \%$ \\
\hline \multicolumn{3}{|c|}{ Orientações sobre temperatura } & \multicolumn{3}{|c|}{ Orientações sobre folga semanal } \\
\hline Sim, detalhadamente & 20 & $10,31 \%$ & Sim, detalhadamente & 74 & $38,14 \%$ \\
\hline Sim, superficialmente & 27 & $13,92 \%$ & Sim, superficialmente & 53 & $27,32 \%$ \\
\hline Não & 147 & $75,77 \%$ & Não & 67 & $34,54 \%$ \\
\hline \multicolumn{3}{|c|}{ Orientações sobre postura } & \multicolumn{3}{|c|}{ Fornecimento de Ferramentas } \\
\hline Sim, detalhadamente & 41 & $21,13 \%$ & Algumas & 73 & $37,63 \%$ \\
\hline Sim, superficialmente & 49 & $25,26 \%$ & Não & 34 & $17,53 \%$ \\
\hline Não & 104 & $53,61 \%$ & Todas & 87 & $44,85 \%$ \\
\hline
\end{tabular}


Tabela 2 - Tabela de frequência das orientações das empresas

(conclusão)

Orientações sobre adequação de mesa Orientações sobre periféricos externos

\begin{tabular}{lcclll}
\hline Sim, detalhadamente & 36 & $18,56 \%$ & Não & 88 & $56,41 \%{ }^{*}$ \\
Sim, superficialmente & 36 & $18,56 \%$ & Sim & 68 & $43,59 \%^{*}$ \\
Não & 122 & $62,89 \%$ & Não utilizo notebook & 38 & \\
\hline \multicolumn{2}{l}{ Orientações sobre adequação de assento } & ${ }^{*}$ Considerando apenas os que & & \\
\hline Utilizam notebook & & & \\
Sim, detalhadamente & 33 & $17,01 \%$ & & & \\
Não & 36 & $18,56 \%$ & & &
\end{tabular}

Fonte: Autoria Própria (2020)

Figura 2 - Figura de Gráficos das orientações das empresas

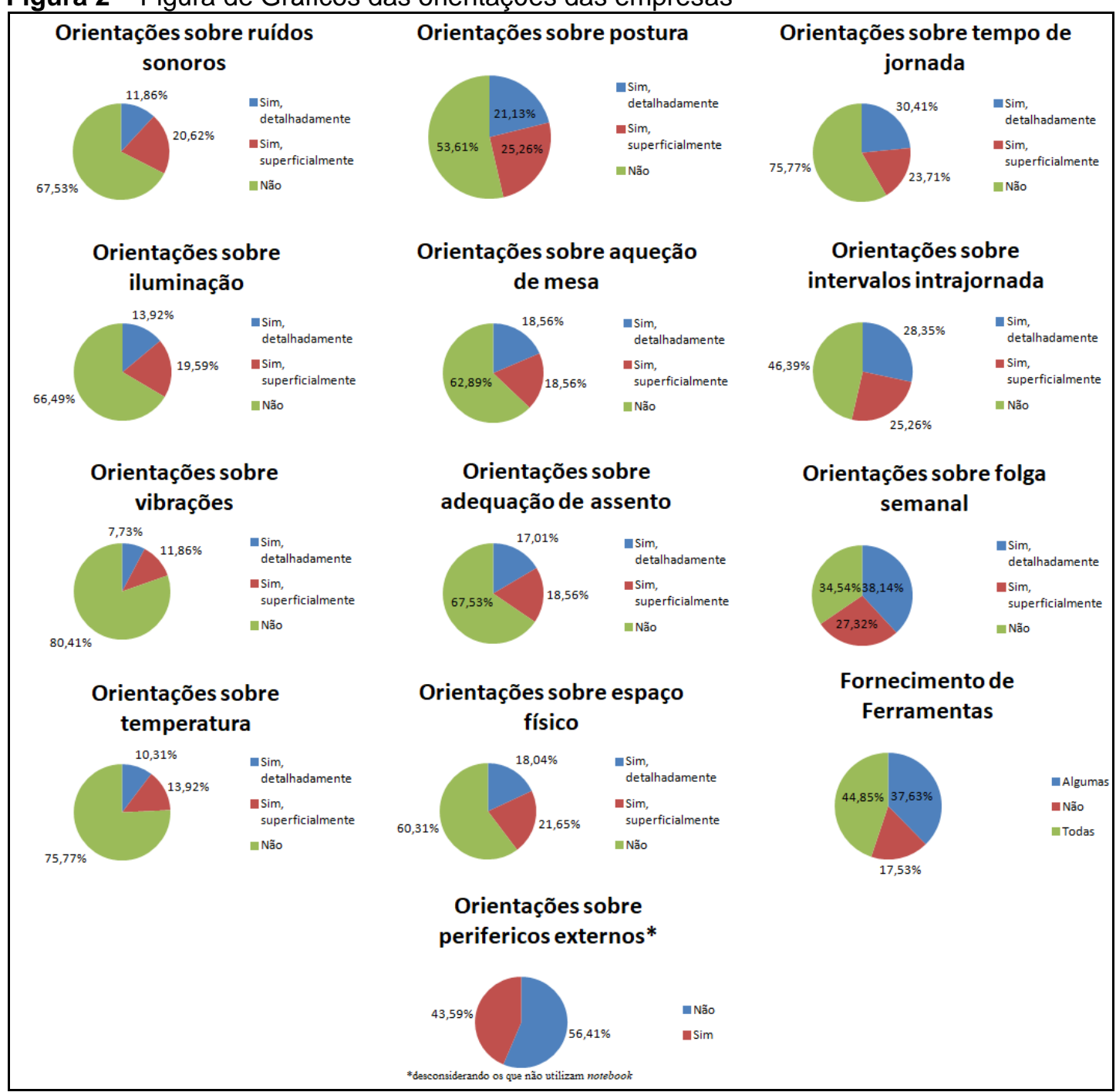

Fonte: Autoria Própria (2020)

Por sua vez, a terceira parte do questionário abordava se os teletrabalhadores estariam tomando os cuidados ergonômicos necessários em um ambiente de teletrabalho. Ato contínuo, foi constatado que $16(8 \%)$ indivíduos não estariam 
tomando cuidado em nenhum dos temas abordados neste estudo, sendo que 19 (10\%) admitiram se preocupar com todos os temas abordados, tendo o que pode ser caracterizado ao menos como um cuidado parcial. Com auxílio da Tabela 3 e Figura 3 , foi constatado que, de forma geral, as menores preocupações com os cuidados no ambiente do teletrabalhador são em relação às vibrações $(61 \%)$ e aos alongamentos e ginástica laboral (63\%), enquanto que se considerarmos apenas aqueles que tiveram algum tipo de cuidado, os temas de maior cautela são: folga semanal $(77 \%)$, intervalo intrajornada $(69 \%)$, utilização de périfericos no notebook (68\% daqueles que utilizam notebook), iluminação (67\%), utilização de espaço físico predeterminado $(66 \%)$, postura corporal $(65 \%)$ e adequação da mesa de trabalho (63\%). Entre os indivíduos que alegaram estar tomando parcialmente os cuidados questionados, as maiores preocupações estão na postura corporal $(50 \%)$, intervalos intrajornada $(41 \%)$ e ruídos sonoros $(40 \%)$, já entre aqueles que admitiram tomar total cuidado, os temas principais são as folgas semanais (45\%), utilização de espaço físico preestabelecido (36\%) e iluminação (29\%).

Em uma pesquisa similar sobre ergonomia e home office, restou demonstrado que as adaptações mais recorrentes nos ambientes de teletrabalho dos indivíduos foram com implementos relacionados à iluminação, mesas, cadeiras e algumas adaptações de ambiente propriamente dito (CASTAÑO, 2016), sendo assim, é possível se depreender que as preocupações dos entrevistados são bastante semelhantes às preocupações dos teletrabalhadores questionados no presente trabalho.

Tabela 3 - Tabela de frequência dos cuidados tomados pelos profissionais (conitnua)

\begin{tabular}{lcclcc}
\hline \multicolumn{2}{l}{ Cuidados com ruídos sonoros } & \multicolumn{4}{l}{ Cuidado com o espaço físico } \\
\hline Não & 78 & $40 \%$ & Não & 66 & $34 \%$ \\
Parcialmente & 79 & $41 \%$ & Parcialmente & 58 & $30 \%$ \\
Totalmente & 37 & $19 \%$ & Totalmente & 70 & $36 \%$ \\
\hline Cuidados com iluminação & & Cuidado com intervalo intrajornada \\
\hline Não & 64 & $33 \%$ & Não & 60 & $31 \%$ \\
Parcialmente & 74 & $38 \%$ & Parcialmente & 81 & $42 \%$ \\
Totalmente & 56 & $29 \%$ & Totalmente & 53 & $27 \%$ \\
\hline Cuidado com vibrações & & & Cuidado com folga semanal & \\
\hline Não & 119 & $61 \%$ & Não & 44 & $23 \%$ \\
Parcialmente & 49 & $25 \%$ & Parcialmente & 61 & $31 \%$ \\
Totalmente & 26 & $13 \%$ & Totalmente & 89 & $46 \%$ \\
\hline
\end{tabular}


Tabela 3 - Tabela de frequência dos cuidados tomados pelos profissionais (conclusão)

\begin{tabular}{lcclcl}
\hline \multicolumn{4}{l}{ Cuidado com temperatura } & \multicolumn{5}{l}{ Cuidado com ginástica laboral } \\
\hline Não & 84 & $43 \%$ & Não & 122 & $63 \%$ \\
Parcialmente & 63 & $32 \%$ & Parcialmente & 58 & $30 \%$ \\
Totalmente & 47 & $24 \%$ & Totalmente & 14 & $7 \%$ \\
\hline \multicolumn{2}{l}{ Cuidado com postura corporal } & & Cuidado com Periféricos & \\
\hline Não & 68 & $35 \%$ & Não & 49 & $31 \%$ \\
Parcialmente & 98 & $51 \%$ & Parcialmente & 39 & $25 \%$ \\
Totalmente & 28 & $14 \%$ & Totalmente & 68 & $44 \%$ \\
\hline Cuidado com a mesa & & & Locais não ergonômicos & \\
\hline Não & 72 & $37 \%$ & Não & 85 & $44 \%$ \\
Parcialmente & 77 & $40 \%$ & Parcialmente & 59 & $30 \%$ \\
Totalmente & 45 & $23 \%$ & Totalmente & 50 & $26 \%$ \\
\hline \multicolumn{2}{l}{ Cuidado com o assento } & & & ${ }^{*}$ Considerando apenas os & \\
\hline Não & 74 & $38 \%$ & & & \\
Parcialmente & 78 & $40 \%$ & & & \\
Totalmente & 42 & $22 \%$ & &
\end{tabular}

Fonte: Autoria Própria (2020)

Figura 3 - Figura de gráficos dos cuidados tomados pelos profissionais

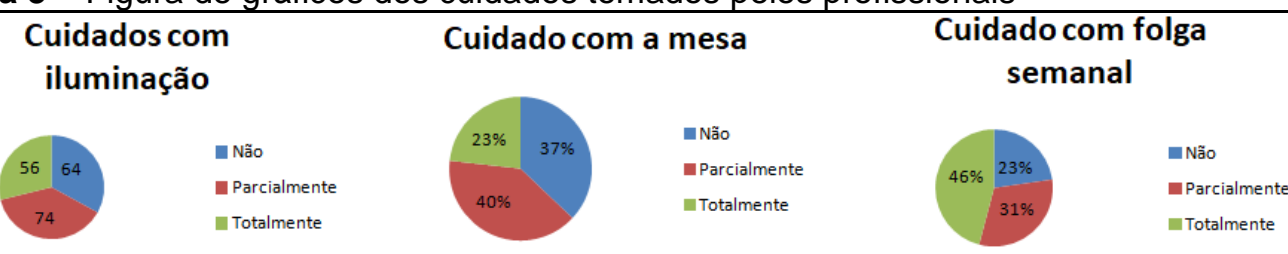

Cuidado com vıbrações

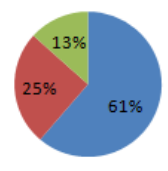

๓กล̃o

n Parcialmente

nivtotalmente

Cuidado com temperatura

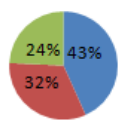

Cuidado com o assento

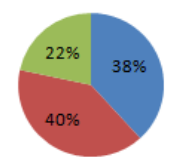

Cuidado com o espaço físico

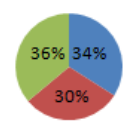

แกล̃o

- Parcialmente

w Totalmente

- Parcialment

wotalmente

Cuidado com Periféricos*

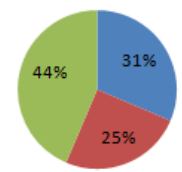

— Não

- Parcialmente

ntotalmente
Cuidado com ginástica laboral

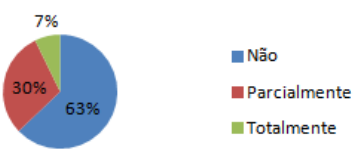

Locais não ergonomicos

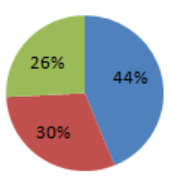

घ Não

- Parcialmente

-

Fonte: Autoria Própria (2020)

Revista Produção Online. Florianópolis, SC, v. 20, n. 4, p. 1405-1434, 2020. 
Por fim, a última parte do questionário abordava sobre as dores sentidas pelo teletrabalhadores: se elas iniciaram antes ou após a pandemia, e com qual frequência eles utilizam medicamentos para trabalhar. $O$ formulário interrogava sobre as dores em locais específicos e pediam para o teletrabalhador classificar, em uma escala de 1 a 5 , em que 1 é menor dor e 5 maior dor, qual a intensidade da dor sentida. Realizando uma média e mediana dessas escalas, visualizamos no Quadro 2 que, de forma geral, a dor mais forte sentida é na região das costas, seguida por dor de cabeça, dores no pescoço e ombros, respectivamente.

Quadro 2 - Média e Mediana de escala das dores

\begin{tabular}{|c|c|c|c|c|c|c|c|c|c|c|c|}
\cline { 2 - 11 } \multicolumn{1}{c|}{} & $\begin{array}{c}\text { Dor no } \\
\text { Pescoço }\end{array}$ & $\begin{array}{c}\text { Dor } \\
\text { no } \\
\text { Braço }\end{array}$ & $\begin{array}{c}\text { Dor nos } \\
\text { Ombros }\end{array}$ & $\begin{array}{c}\text { Dor nos } \\
\text { Cotovelos }\end{array}$ & $\begin{array}{c}\text { Dor } \\
\text { nos } \\
\text { Punhos }\end{array}$ & $\begin{array}{c}\text { Dor } \\
\text { nas } \\
\text { Costas }\end{array}$ & $\begin{array}{c}\text { Dor no } \\
\text { Quadril }\end{array}$ & $\begin{array}{c}\text { Dor } \\
\text { na } \\
\text { Perna }\end{array}$ & $\begin{array}{c}\text { Dor no } \\
\text { Pés/Tornozelo }\end{array}$ & $\begin{array}{c}\text { Dor de } \\
\text { Cabeça }\end{array}$ & $\begin{array}{c}\text { Desconforto } \\
\text { Estomacal }\end{array}$ \\
\hline Média & 2,22 & 1,78 & 2,09 & 1,32 & 1,79 & 2,96 & 1,82 & 1,78 & 1,48 & 2,43 & 1,71 \\
\hline Mediana & 2,00 & 1,00 & 2,00 & 1,00 & 1,00 & 3,00 & 1,00 & 1,00 & 1,00 & 2,00 & 1,00 \\
\hline
\end{tabular}

Fonte: Autoria Própria (2020)

Também foi constatado que as costas são as regiões em que mais entrevistados reclamam de algum tipo de dor, independentemente de seu nível, 163 $(84 \%)$ entrevistados alegam sentir dor nesse local. Interessante observar-se que, no trabalho de Castaño et. Al. (2016), as costas também foram o local de maior reclamação dos teletrabalhadores, mostrando que, pouco mudou em relação à correção postural dos indivíduos nesses 4 anos. A dor de cabeça é a de maior reclamação no que concerne à intensidade das dores, sendo que $23(12 \%)$ indivíduos reclamam de dor extrema. Por outro lado, as regiões com menor índice de reclamação de dor são os cotovelos com 147 (75\%) pessoas não apresentando nenhum desconforto, seguido pela dor nos pés e/ou tornozelos quando esse número cai para $138(71 \%)$ sujeitos.

De acordo com a Figura 4, dos participantes do questionário, apenas 10 (5\%) dizem não sentir dor em região alguma, e somente 5 sentem dor em apenas uma região (2 cabeça, 1 quadril, 1 pernas e 1 estômago). A maioria tem a perspectiva de que as dores experenciadas estão relacionadas com o trabalho, com $58(30 \%)$ pessoas afirmando ter certeza que a dor estaria relacionada ao trabalho, $97(50 \%)$ achando que talvez, e apenas 39 (20\%) trabalhadores que alegam não acreditar que a dor sentida esteja relacionada com sua atividade profissional. 
Figura 4 - Figura de gráficos da intensidade das dores localizadas

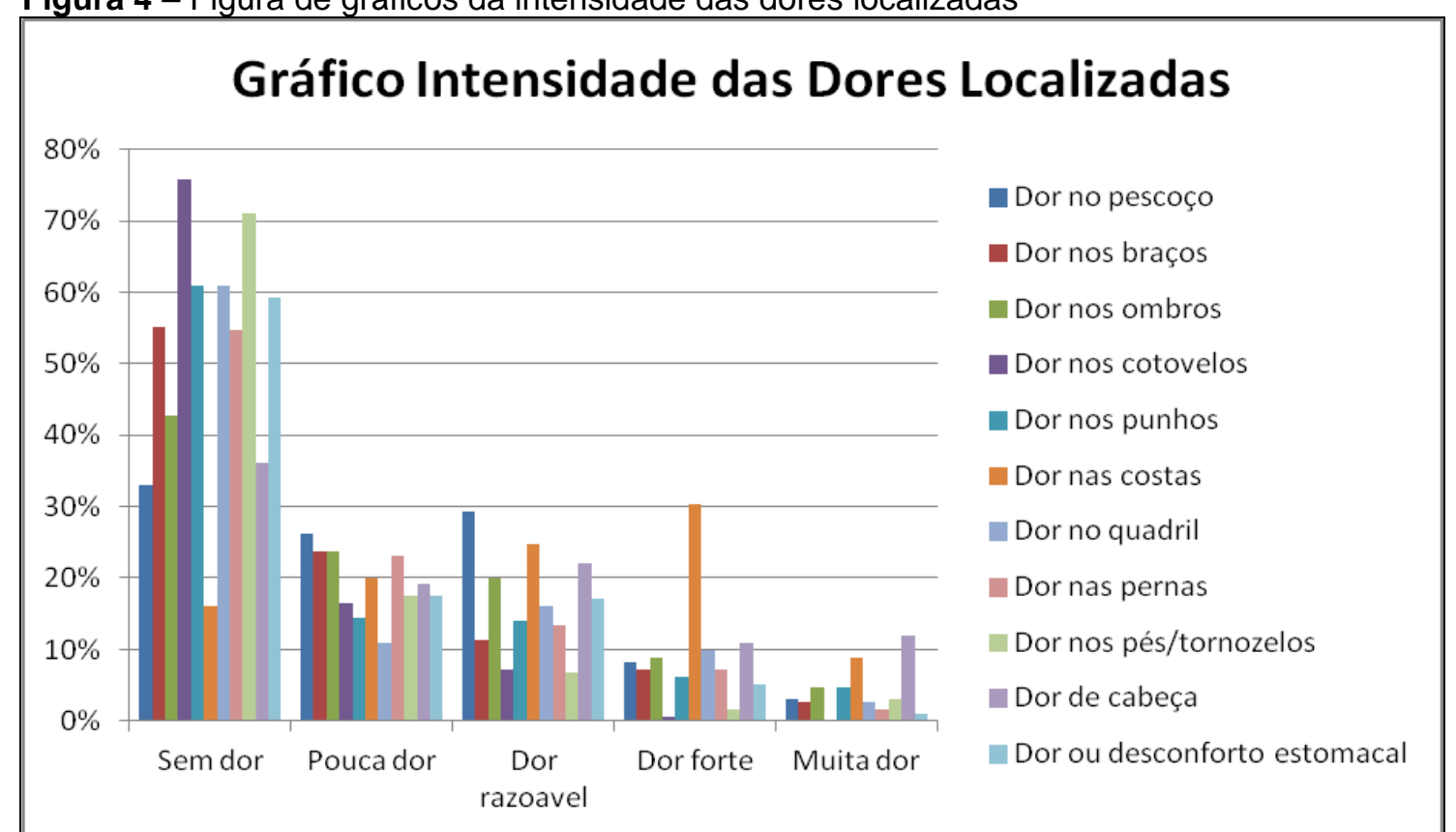

Fonte: Autoria Própria (2020)

Do total de entrevistados, 111 (57\%) afirmam que as dores já preexistiam, e 54 (sendo $28 \%$ do total e $65 \%$ dos que reclamam de dores pós-teletrabalho) que as dores começaram em até 2 semanas após o início do teletrabalho. Ainda, 24 (12\%) indivíduos argumentam que a dor nunca aumenta com o a execução da atividade laboral, enquanto $14(7 \%)$ dizem que a dor sempre aumenta com o trabalho, 147 (75\%) pessoas reclamam que as dores aumentam com determinada frequência durante o serviço. Dentre os participantes deste estudo, 21 (11\%) trabalhadores garantem sofrer de dores crônicas, ou seja, que não melhoram com o tempo, 76 (39\%) dizem que geralmente a dor melhora apenas pela noite e $52(27 \%)$ pessoas vêem alguma melhora somente ao chegar o descanso semanal. Por fim, 124 (64\%) sujeitos dizem não haver necessidade de usar medicamento ou compressa quando trabalham, e apenas $10(5 \%)$ utilizam o artifício com alta frequência, como podemos observar na Figura 5. 
Figura 5 - Figura de gráficos relacionado as dores dos teletrabalhadores

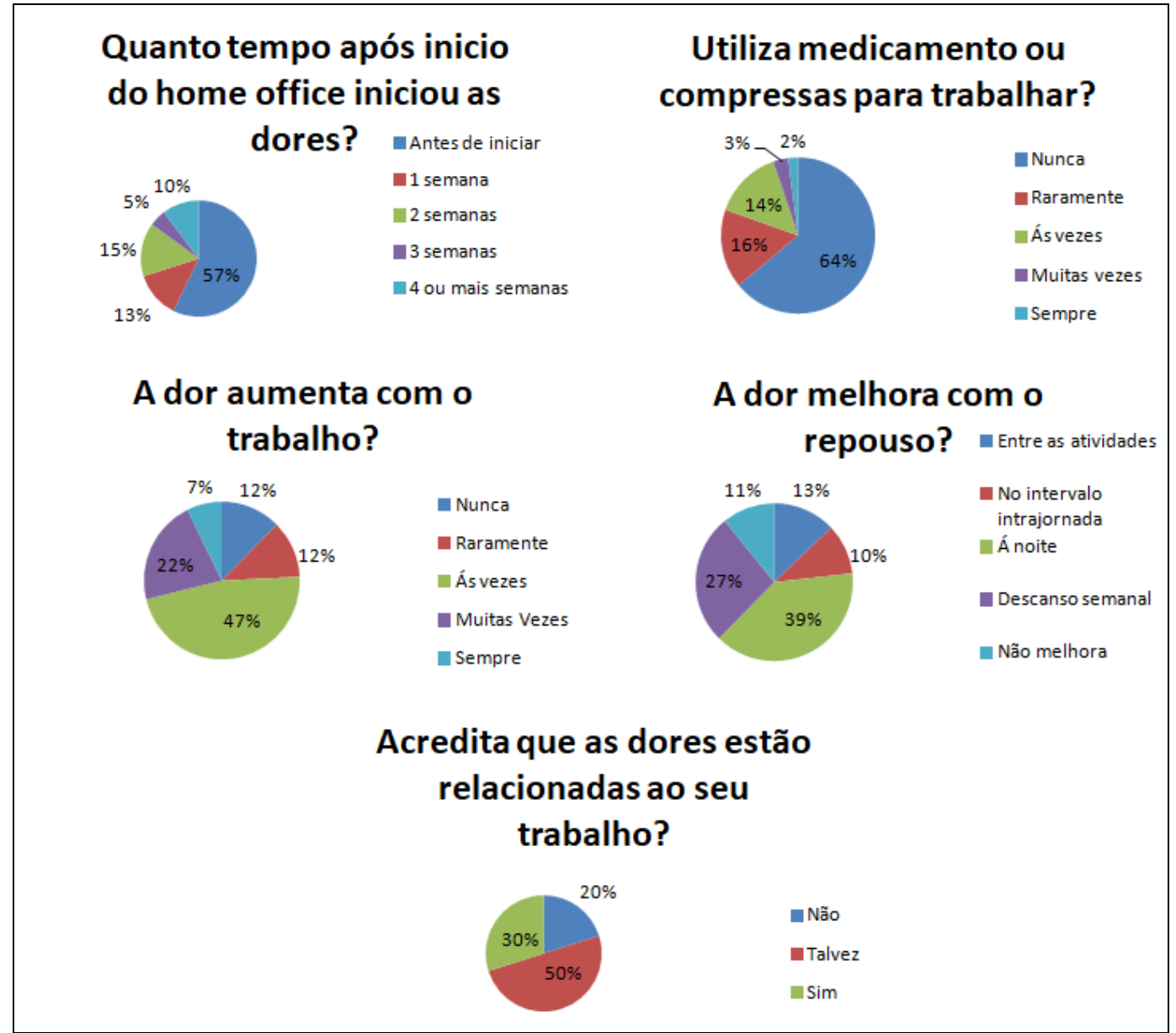

Fonte: Autoria Própria (2020)

\subsection{Relações das Variavéis}

Nesta etapa foi utilizada a ferramenta tabela dinâmica do software excel, a fim de comparar, cruzar e analisar os dados, de forma a buscar possíveis relações entre os cuidados tomados e as orientações propostas pelos empregadores. Inicialmente, analisaremos se a recomendação ou não recomendação impactua em boas práticas ergonômicas pelos teletrabalhadores, comparando assim, cada tema entrevistado, isoladamente. Nesta etapa as variavéis de recomendações "Sim, superficialmente" e "Sim, detalhadamente" se agruparão em uma nova variável: "Sim".

Sendo assim, analisando os resultados na Tabela 4, percebeu-se que, quando não são orientados a respeito de algum tema, pelo menos $43 \%$ dos trabalhadores acabam não realizando cuidado algum em relação a ele. Esse número variou de $43 \%$ em temas como postura e iluminação e atingiu o patamar de $78 \%$ 
quando se tratava de alongamentos e ginástica laboral. Em contrapartida, no grupo que recebeu algum tipo de orientação, a porcentagem dos trabalhadores que não tomavam os devidos cuidados em relação a cada tema variou de $9 \%$ quando o assunto era folga semanal até $31 \%$ no tema de alongamento e ginástica laboral, que se tornou o tópico de cartilha mais negligenciado pelos teletrabalhadores.

Quando realizada uma média simples de todos os temas ergonômicos entre os dois grupos (os que receberam e os que não receberam orientação nenhuma), obtemos o resultado de que, em média $52 \%$ do grupo que não recebeu orientação acerca de determinado assunto, não toma cuidado algum neste tema, enquanto que, no grupo que teve alguma orientação repassada, essa média numérica cai para 18\% dos trabalhadores que não tomaram os cuidados recomendados. Também podemos observar que, em todos os tópicos, o número de indivíduos que não recebeu orientação alguma e optaram por não tomar nenhum dos cuidados, é sempre consideravelmente superior ao número de indivíduos que não tomaram os devidos cuidados, tendo recebido alguma orientação.

Tabela 4 - Tabela de frequência dos cuidados nos grupos com e sem orientação em cada tema

(conitnua)

\begin{tabular}{l|c|c|l|c|c}
\hline RUíDOS SONOROS & Sem Orientação & Com Orientação & ILUMINAÇÃo & Sem Orientação & Com Orientação \\
\hline Sem cuidado & $47 \%$ & $25 \%$ & Sem cuidado & $43 \%$ & $14 \%$ \\
Algum cuidado & $39 \%$ & $44 \%$ & Algum cuidado & $37 \%$ & $40 \%$ \\
Todo cuidado & $14 \%$ & $30 \%$ & Todo cuidado & $20 \%$ & $46 \%$ \\
\hline VIBRAçÕES & Sem Orientação & Com Orientação & TEMPERATURA & Sem Orientação & Com Orientação \\
\hline Sem cuidado & $71 \%$ & $21 \%$ & Sem cuidado & $52 \%$ & $15 \%$ \\
Algum cuidado & $20 \%$ & $47 \%$ & Algum cuidado & $32 \%$ & $34 \%$ \\
Todo cuidado & $9 \%$ & $32 \%$ & Todo cuidado & $16 \%$ & $51 \%$ \\
\hline POSTURA & Sem Orientação & Com Orientação & MESA & Sem Orientação & Com Orientação \\
\hline Sem cuidado & $43 \%$ & $26 \%$ & Sem cuidado & $48 \%$ & $18 \%$ \\
Algum cuidado & $46 \%$ & $56 \%$ & Algum cuidado & $34 \%$ & $50 \%$ \\
Todo cuidado & $11 \%$ & $19 \%$ & Todo cuidado & $18 \%$ & $32 \%$ \\
\hline ASSENTO & Sem Orientação & Com Orientação & FŚ́SIÇO & Sem Orientação & Com Orientação \\
\hline Sem cuidado & $47 \%$ & $22 \%$ & Sem cuidado & $47 \%$ & $14 \%$ \\
Algum cuidado & $37 \%$ & $46 \%$ & Algum cuidado & $27 \%$ & $34 \%$ \\
Todo cuidado & $16 \%$ & $32 \%$ & Todo cuidado & $26 \%$ & $52 \%$ \\
\hline INTERVALO & Sem Orientação & Com Orientação & FOLGAS & Sem Orientação & Com Orientação \\
\hline Sem cuidado & $53 \%$ & $12 \%$ & Sem cuidado & $49 \%$ & $9 \%$ \\
Algum cuidado & $36 \%$ & $47 \%$ & Algum cuidado & $28 \%$ & $33 \%$ \\
\hline
\end{tabular}

Revista Produção Online. Florianópolis, SC, v. 20, n. 4, p. 1405-1434, 2020. 
Tabela 4 - Tabela de frequência dos cuidados nos grupos com e sem orientação em cada tema

(conclusão)

\begin{tabular}{l|c|c|l|c|c}
\hline ALONGAMENTOS & Sem Orientação & Com Orientação & PERIFÉRICOS* $^{\star}$ & Sem Orientação & Com Orientação \\
\hline Sem cuidado & $78 \%$ & $31 \%$ & Sem cuidado & $45 \%$ & $13 \%$ \\
Algum cuidado & $21 \%$ & $48 \%$ & Algum cuidado & $26 \%$ & $24 \%$ \\
Todo cuidado & $1 \%$ & $21 \%$ & Todo cuidado & $28 \%$ & $63 \%$ \\
\hline
\end{tabular}

Fonte: Autoria Própria (2020)

\section{CONSIDERAÇÕES FINAIS}

Em consonância com o estudo realizado com base nas regras e procedimentos da ergonomia, frente ao cenário atual de isolamento social, decorrente da pandemia por COVID-19, pode-se observar que, embora a questão da saúde laboral seja regulamentada e difundida há tempos, sua aplicabilidade ainda é deficitária e negligenciada tanto pelas empresas, quanto pelos trabalhadores.

O teletrabalho já vinha conquistando espaço no mercado e, com a atual situação mundial, em que os países decretaram quarentena como medida preventiva e paliativa do contágio do vírus em questão, tornou-se essencial para a continuidade das atividades laborais.

Sendo assim, o mercado necessitou se adaptar de prontidão, colocando alguns trabalhadores em condições desfavoráveis de trabalho, no que tange à ergonomia. Infelizmente, pôde-se observar que, de forma geral, as empresas pouco se preocupam em orientar seus empregados no aspecto ergonômico, seja por acreditar que eles já detenham esse conhecimento, seja pelo fato de o próprio empregador desconhecer o tema e/ou não lhe dar a devida importância.

Considerando a análise da pesquisa, é importante destacar que os profissionais cujas empresas forneceram recomendações e informações sobre ergonomia obtiveram maior consciência e cuidado em propiciar uma estação laboral mais adaptada às suas demandas profissionais, do que os trabalhadores que não receberam informação alguma de suas empresas. Ainda assim, ressalta-se que, quase metade dos trabalhadores, apesar de suas empresas negligenciarem nas questões relativas à ergonomia, ainda tomaram alguns cuidados nas adaptações do ambiente doméstico ao teletrabalho.

A análise dos resultados mostrou que $82 \%$ dos profissionais que recebem orientação acerca de um tema ergonômico tendem a tomar os cuidados necessários 
com este tema, em contrapartida, apenas $48 \%$ daqueles que não recebem a respectiva orientação também tomam cuidados. Os itens que, mesmo sem as devidas orientações, os profissionais mais se preocupam são a postura e a iluminação, fatores que influenciam diretamente nas dores mais reclamadas, nas regiões das costas e da cabeça.

Por algum motivo a ginástica laboral é o item mais negligenciado por todos, talvez pelo fato de que muitos empregados podem praticar atividades físicas com relativa frequência e não veem a necessidade da ginástica laboral; ou talvez porque os empregadores suponham que a realização poderá tomar tempo do trabalhador e vir a reduzir sua produtividade.

A folga e o intervalo são os temas mais respeitados pelo trabalhador, provavelmente por já ter se tornado um hábito que adveio de uma obrigação legal, e portanto um direito do trabalhador. A postura corporal é um dos itens mais abordados por ambos, quiçá pela maior exposição em trabalhos midiáticos, ou pela dor nas costas ser uma das maiores reclamações dos trabalhadores. 1 em cada 20 profissionais em teletrabalho alega utilizar medicamento com frequência para trabalhar, e a maioria afirma não só que as dores que sentem aumentam durante a jornada, como desconfiam que elas estão relacionadas com o exercício profissional.

Traçando um paralelo entre as recomenções ergonômicas dos empregadores e as práticas adotadas ou não pelos empregados, mediante a análise estatística, restou evidenciado que as recomendações do empregador aos empregados das adequações ergonômicas condicionam maior consciência e respeito aos procedimentos, assegurando maior/melhor salubridade no desempenho das atividades. Sendo assim, acredita-se que a normatização em instrumentalizar esta recomendação poderia atingir um percentual ainda maior de cuidado dos trabalhadores para adequar sua estação de trabalho, tendo em vista que as empresas poderiam dispor destas recomendações escritas e cientificadas pelo teletrabalhador.

Considerando que a ergonomia encontra-se respaldada na legislação brasileira, a burocratização deste instrumento tende a ser ainda mais consistente e efetiva, tanto para a empresa, quanto para o teletrabalhador nos quesitos de conhecimento, segurança e salubridade, podendo ser oficializado mediante registro escrito e assinatura do teletrabalhador como recomendação técnica e essencial para 
atividades laborais em teletrabalho. Isto asseguraria que o trabalhador adaptasse sua estação com o fim de otimizar as condições de trabalho, bem como resguardaria a empresa juridicamente, caso seu empregado descumpra a recomendação e venha sofrer com alguma comorbidade decorrente desta negligência.

Nesse sentido, para futuras pesquisas este estudo pode se tornar fonte relevante de informações tanto para empresas que desejam implementar o teletrabalho, quanto para pesquisadores da área a fim de comparar dados, ou ainda aprofundar a pesquisa, em aspectos específicos, ou ainda estabelecer um estudo comparativo de empresas que normatizam as recomendações técnicas e de empresas que não adotam a burocratização da normativa.

\section{REFERÊNCIAS}

ABERGO. O que é ergonomia. Disponível em:

http://www.abergo.org.br/internas.php?pg=0 que e ergonomia. Acesso em: 25 abr. 2020.

ANTUNES, R. Adeus ao trabalho? Ensaios sobre as metamorfoses e a centralidade do mundo do trabalho. 2. ed. São Paulo: Cortez, 1995.

BRASIL. Ministério do Trabalho e Emprego. NR 17- Ergonomia. Brasília: Ministério do Trabalho e Emprego, 2015. Disponível em:

https://enit.trabalho.gov.br/portal/images/Arquivos SST/SST NR/NR-17.pdf. Acesso em: 28 jul. 2020.

BRASIL. Lei no 13.467/2017, de 13 de julho de 2017. Altera a Consolidação das Leis do Trabalho (CLT). Diário Oficial da República Federativa do Brasil. Brasília, DF, 14.jul.2017. Disponível em: http://www.planalto.gov.br/ccivil 03/ ato2015-

2018/2017/lei/l13467.htm. Acesso em: 28 jul. 2020.

CASTAÑON, J. A. B, et al. O home office e a ergonomia nas condições de trabalho e saúde de arquitetos e engenheiros. Blucher Engineering Proceedings, v. 3, n. 3, p. 643-654, 2016.

CERVO, A. L.; BERVIAN, P. A.; SILVA, R. D. Metodologia cientifica. 6. ed. São Paulo: Pearson, 2007.

CRISTALDO, J. B. Leitor de Lobato. Jornal Folha de S. Paulo, Caderno Mais!, 28/06/1998, p 5.

ÉPOCA. Após Yahoo!, Best Buy também acaba com home office. Revista Época, 06 mar. 2013.

GRECO, M. A.; MARTINS, I. G. S. Direito e Internet: relações jurídicas na 
sociedade informatizada. São Paulo: Revista dos Tribunais, 2001.

IIDA, I. Ergonomia projeto e produção. 2. ed. São Paulo: Edgard Blucher, 2005

JARDIM, C. C. S. O teletrabalho e suas atuais modalidades. São Paulo: LTr, 2003.

KANTER R. M. Work pray love. Havard Business Review, p. 38, dec. 2010.

KUGELMASS, J. Teletrabalho: novas oportunidades para o trabalho flexível. São Paulo: Atlas, 1996.

MANOOCHEHRI, G.; PINKERTON, T. Managing telecommuters: opportunities and challenges. American Business Review. California State University, Fullerton, 2003.

MARTÍNEZ-SÁNCHEZ, A. et al. Telework, human resource flexibility and firm performance. New Technology, Work and Employment, v. 22, n. 3, p.208-223, 2007. https://doi.org/10.1111/j.1468-005X.2007.00195.x

MIRA, T. M. O teletrabalho: a qualidade de vida em questão. INNOVARE, Ponta Grossa: Cescage, 2004.

OLIVEIRA, M.M.V. Ergonomia e o teletrabalho a domicílio. Dissertação (Mestrado) - Universidade Federal de Santa Catarina. Florianópolis, 1996.

PÉREZ, M. P. et al. A technology acceptance modelo $f$ innovation adoption: the case of teleworking. European Journal of Innovation Management, v. 7, n. 4, p. 280291, 2004. https://doi.org/10.1108/14601060410565038

RICHARDSON, R. J. Pesquisa social: métodos e técnicas. São Paulo: Atlas, 1999.

SANTOS, E.M; SILVA, A.B.S; CARVALHO, P.P.S. Análise ergonômica de um posto de trabalho: um estudo de caso em uma biblioteca pública.Coletânea Nacional sobre Engenharia de Produção 6: Ergonomia e Segurança do Trabalho, Gestão do Produto e Gestão Econômica, 2017 pag 39-51

SHIN, B.; SHENG, O.; HIGA K. Telework: existing research and future directions. Journal of Organizational Computing and Electronic Commerce, v. 10, n. 2, p. 85-101, 2000. https://doi.org/10.1207/S15327744JOCE1002 2

SILVERMAN, D. Interpretação de dados qualitativos: métodos para análise de entrevistas, textos e interações. Porto Alegre: artmed, 2009.

SOARES, AGB; MEDEIROS, M.K.S; NETO, M.L.Q. Análise e avaliaçõa ergonômica das condições de trabalho em uma agência bancária. Coletânea Nacional sobre Engenharia de Produção 6: Ergonomia e Segurança do Trabalho, Gestão do Produto e Gestão Econômica, 2017 pag 39-51

SOUZA, M. R. S. Habitação e informatização: o teletrabalho. São Carlos: UFSCar, 
2005.

SPERANDIO, J.C. Contribuições contemporâneas da psicologia cognitiva e da inteligência artificial para a ergonomia da informática. Análise Psicológica (1989), 1- 2-3 (Vn): 231-243

VALOR. $43 \%$ das empresas adotam home office devido ao coronavírus. Disponível em: https://valor.globo.com/carreira/noticia/2020/03/20/43percent-dasempresas-adotam-home-office-devido-ao-coronavirus.ghtml. Acesso em: 28 abr. 2020.

VERGARA, S. C. Métodos de pesquisa em administração. São Paulo: Atlas, 2005.

VIDAL, M. C. Introdução à ergonomia. Curso superior de especialização em ergonomia contemporânea. Rio de Janeiro: CESERG/GENTE/COPPE/UFRJ, 2000.

WORLD ECONOMIC FORUM. 6 Charts That Show What Employers and Employees Really Think About Remote Working. Disponível em: https://www.weforum.org/agenda/2020/06/coronavirus-covid19-remote-workingoffice-employees-employers. Acesso em: 01 ago 2020.

WINTER, V. R. L. Teletrabalho: uma forma alternativa de emprego. São Paulo: LTr, 2005.

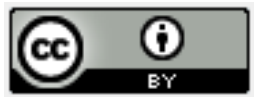

Artigo recebido em: 01/10/2020 e aceito para publicação em: 13/12/2020

DOI: http://dx.doi.org/10.14488/1676-1901. v20i4.4146 
APÊNDICE - Questionário de Pesquisa de Campo

\begin{tabular}{|c|c|c|c|c|}
\hline \multicolumn{5}{|c|}{ DADOS PESSOAIS } \\
\hline \multicolumn{5}{|c|}{ SEXO } \\
\hline & Masculino & & Feminino & \\
\hline \multicolumn{5}{|c|}{ IDADE } \\
\hline$<21$ & $22-34$ & $35-47$ & $48-60$ & $>60$ \\
\hline \multicolumn{5}{|c|}{ Grau de Instrução } \\
\hline Fundamental & Médio/Técnico & Superior Incompleto & Superior Completo & Pós Graduado \\
\hline \multicolumn{5}{|c|}{ DADOS DO CARGO } \\
\hline \multicolumn{5}{|c|}{ Tipo de Hierarquia } \\
\hline Operacional & & Gerência & & Direção \\
\hline \multicolumn{5}{|c|}{ Tipo de Contrato } \\
\hline $\begin{array}{l}\text { Funcionário } \\
\text { Público }\end{array}$ & & CLT & & PJ \\
\hline \multicolumn{5}{|c|}{ ORIENTAÇÕES DA EMPRESA SOBRE AMBIENTE DE TRABALHO } \\
\hline \multicolumn{5}{|c|}{ Sobre Ruídos } \\
\hline Não & & $\begin{array}{c}\text { Sim, } \\
\text { Superficialmente }\end{array}$ & & Sim, Detalhadamente \\
\hline \multicolumn{5}{|c|}{ Sobre lluminação } \\
\hline Não & & $\begin{array}{c}\text { Sim, } \\
\text { Superficialmente }\end{array}$ & & Sim, Detalhadamente \\
\hline \multicolumn{5}{|c|}{ Sobre Vibrações } \\
\hline Não & & $\begin{array}{c}\text { Sim, } \\
\text { Superficialmente }\end{array}$ & & Sim, Detalhadamente \\
\hline \multicolumn{5}{|c|}{ Sobre Temperatura } \\
\hline Não & & $\begin{array}{c}\text { Sim, } \\
\text { Superficialmente }\end{array}$ & & Sim, Detalhadamente \\
\hline \multicolumn{5}{|c|}{ Sobre Postura } \\
\hline Não & & $\begin{array}{c}\text { Sim, } \\
\text { Superficialmente }\end{array}$ & & Sim, Detalhadamente \\
\hline \multicolumn{5}{|c|}{ Sobre Adequação da Mesa } \\
\hline Não & & $\begin{array}{c}\text { Sim, } \\
\text { Superficialmente }\end{array}$ & & Sim, Detalhadamente \\
\hline \multicolumn{5}{|c|}{ Sobre Adequação do Assento } \\
\hline Não & & $\begin{array}{c}\text { Sim, } \\
\text { Superficialmente }\end{array}$ & & Sim, Detalhadamente \\
\hline \multicolumn{5}{|c|}{ Sobre Espaço Físico (Utilização apenas de um cômodo pré-determinado) } \\
\hline Não & & $\begin{array}{c}\text { Sim, } \\
\text { Superficialmente }\end{array}$ & & Sim, Detalhadamente \\
\hline \multicolumn{5}{|c|}{ Foi fornecido as ferramentas necessárias para a realização do trabalho? } \\
\hline Não & & Algumas & & Todas \\
\hline \multicolumn{5}{|c|}{ Foi recomendado tempo máximo de trabalho diário? } \\
\hline Não & & $\begin{array}{c}\text { Sim, } \\
\text { Superficialmente }\end{array}$ & & Sim, Detalhadamente \\
\hline \multicolumn{5}{|c|}{ Foi recomendado tempo de intervalos? } \\
\hline Não & & $\begin{array}{c}\text { Sim, } \\
\text { Superficialmente }\end{array}$ & & Sim, Detalhadamente \\
\hline \multicolumn{5}{|c|}{ Foi recomendado a manutenção das folgas (descanso semanal) } \\
\hline Não & & $\begin{array}{c}\text { Sim, } \\
\text { Superficialmente }\end{array}$ & & Sim, Detalhadamente \\
\hline \multicolumn{5}{|c|}{ Foi recomendado a realização de alongamento antes, durante ou após o trabalho? } \\
\hline Não & & Sim, & & Sim, Detalhadamente \\
\hline
\end{tabular}

Revista Produção Online. Florianópolis, SC, v. 20, n. 4, p. 1405-1434, 2020. 
Superficialmente

No caso de utilização de notebooks, foi recomendando a utilização de periféricos(mouse/teclado) externos?

Não utilizo

Não

$\operatorname{Sim}$

\section{ESTÁ SEGUINDO AS ORIENTAÇÕES OU TOMANDO CUIDADO COM AS QUESTÕES}

\begin{tabular}{|c|c|c|c|c|}
\hline \multicolumn{5}{|c|}{ Sobre Ruídos } \\
\hline Não & & Parcialmente & & Totalmente \\
\hline \multicolumn{5}{|c|}{ Sobre lluminação } \\
\hline Não & & Parcialmente & & Totalmente \\
\hline \multicolumn{5}{|c|}{ Sobre Vibrações } \\
\hline Não & & Parcialmente & & Totalmente \\
\hline \multicolumn{5}{|c|}{ Sobre Temperatura } \\
\hline Não & & Parcialmente & & Totalmente \\
\hline \multicolumn{5}{|c|}{ Sobre Postura } \\
\hline Não & & Parcialmente & & Totalmente \\
\hline \multicolumn{5}{|c|}{ Sobre Mesa } \\
\hline Não & & Parcialmente & & Totalmente \\
\hline \multicolumn{5}{|c|}{ Sobre Assento } \\
\hline Não & & Parcialmente & & Totalmente \\
\hline \multicolumn{5}{|c|}{ Sobre Espaço Físico (Utilização apenas de um cômodo pré-determinado) } \\
\hline Não & & Parcialmente & & Totalmente \\
\hline \multicolumn{5}{|c|}{ Tempo máximo de trabalho diário? } \\
\hline Não & & Parcialmente & & Totalmente \\
\hline \multicolumn{5}{|c|}{ Tempo de intervalos? } \\
\hline Não & & Parcialmente & & Totalmente \\
\hline \multicolumn{5}{|c|}{ Folgas (descanso semanal) } \\
\hline Não & & Parcialmente & & Totalmente \\
\hline \multicolumn{5}{|c|}{ A realização de alongamento antes, durante ou após o trabalho? } \\
\hline Não & & $\begin{array}{c}\text { Sim, } \\
\text { Superficialmente }\end{array}$ & & Sim, Detalhadamente \\
\hline \multicolumn{5}{|c|}{ A utilização de periféricos(mouse/teclado) externos? } \\
\hline Não & & $\begin{array}{c}\text { Sim, } \\
\text { Superficialmente }\end{array}$ & & Sim, Detalhadamente \\
\hline \multicolumn{5}{|c|}{ Você já trabalhou ou trabalha em lugares como deitado na cama ou sentado no banheiro? } \\
\hline Não & & Raramente & & Muitas vezes \\
\hline \multicolumn{5}{|c|}{ MARQUE CASO SINTA DOR/DESCONFORTO } \\
\hline \multicolumn{5}{|c|}{ Dor no Pescoço } \\
\hline Não Sinto & Leve & Moderada & Forte & Muito Forte \\
\hline \multicolumn{5}{|c|}{ Dor nos Braços } \\
\hline Não Sinto & Leve & Moderada & Forte & Muito Forte \\
\hline \multicolumn{5}{|c|}{ Dor nos Ombros } \\
\hline Não Sinto & Leve & Moderada & Forte & Muito Forte \\
\hline \multicolumn{5}{|c|}{ Cotovelo } \\
\hline Não Sinto & Leve & Moderada & Forte & Muito Forte \\
\hline \multicolumn{5}{|c|}{ Punho } \\
\hline Não Sinto & Leve & Moderada & Forte & Muito Forte \\
\hline \multicolumn{5}{|c|}{ Mãos } \\
\hline Não Sinto & Leve & Moderada & Forte & Muito Forte \\
\hline \multicolumn{5}{|c|}{ Dor nas Costas } \\
\hline Não Sinto & Leve & Moderada & Forte & Muito Forte \\
\hline \multicolumn{5}{|c|}{ Dor no Quadril } \\
\hline Não Sinto & Leve & Moderada & Forte & Muito Forte \\
\hline
\end{tabular}

Revista Produção Online. Florianópolis, SC, v. 20, n. 4, p. 1405-1434, 2020. 


\begin{tabular}{|c|c|c|c|c|}
\hline \multicolumn{5}{|c|}{ Dor nas Pernas } \\
\hline Não Sinto & Leve & Moderada & Forte & Muito Forte \\
\hline \multicolumn{5}{|c|}{ Dor nos Tornozelo Pés } \\
\hline Não Sinto & Leve & Moderada & Forte & Muito Forte \\
\hline \multicolumn{5}{|c|}{ Dor de Cabeça } \\
\hline Não Sinto & Leve & Moderada & Forte & Muito Forte \\
\hline \multicolumn{5}{|c|}{ Dor ou desconforto estomacal } \\
\hline Não Sinto & Leve & Moderada & Forte & Muito Forte \\
\hline \multicolumn{5}{|c|}{ Caso tenha respondido que possui dor/desconforto, acredita estar relacionada ao seu trabalho? } \\
\hline Não & & Talvez & & Sim \\
\hline \multicolumn{5}{|c|}{ Há quanto tempo após começar o homeoffice sente dor/desconforto } \\
\hline Antes de Começar & Com 1 Semana & Com 2 semanas & Com 3 semanas & $\begin{array}{c}\text { Com } 4 \text { ou mais } \\
\text { semana }\end{array}$ \\
\hline \multicolumn{5}{|c|}{ O que sente aumenta com o trabalho? } \\
\hline Nunca & Raramente & Ás vezes & Muitas vezes & Sempre \\
\hline \multicolumn{5}{|c|}{ O que sente melhora com repouso? } \\
\hline Entre as atividades & $\begin{array}{l}\text { Nos Intervalos } \\
\text { diários }\end{array}$ & À noite & $\begin{array}{l}\text { Nos finais de } \\
\text { Semana }\end{array}$ & Não Melhora \\
\hline \multicolumn{5}{|c|}{ Você toma medicamento ou realiza compressas para conseguir trabalhar? } \\
\hline Nunca & Raramente & Ás vezes & Muitas vezes & Sempre \\
\hline
\end{tabular}

